\title{
Determination of rat vertebral bone compressive fatigue properties in untreated intact rats and zoledronic-acid-treated, ovariectomized rats
}

\author{
J. E. M. Brouwers • M. Ruchelsman • B. v. Rietbergen • \\ M. L. Bouxsein
}

Received: 30 July 2008 / Accepted: 3 November 2008 / Published online: 9 December 2008

(C) The Author(s) 2008. This article is published with open access at Springerlink.com

\begin{abstract}
Summary Compressive fatigue properties of whole vertebrae, which may be clinically relevant for osteoporotic vertebral fractures, were determined in untreated, intact rats and zoledronic-acid-treated, ovariectomized rats. Typical fatigue behavior was found and was similar to that seen in other species. Fatigue properties were comparable between both groups.

Introduction Osteoporosis is often treated with bisphosphonates, which reduce fracture risk. Effects of bisphosphonates on fatigue strength, which may be clinically relevant for vertebral fractures, are unknown. We determined vertebral, compressive fatigue properties in normal and zoledronic acid (ZOL)-treated, OVX rats.

Methods Thirty-five-week old Wistar rats were divided into SHAM-OVX $(n=7)$ and OVX with ZOL treatment $(n=5$; single injection, $20 \mu \mathrm{g} / \mathrm{kg}$ b.w. s.c.). After 16 weeks, vertebral trabecular microarchitecture and cortical thickness were determined using micro-CT. Vertebrae were cyclically compressed in load-control at $2 \mathrm{~Hz}$ starting at $0.75 \%$ apparent strain. A line parallel to the apparent strain curve was drawn at $0.5 \%$ higher offset, after which the intersection was defined as the time to failure and the apparent strain at failure. Data were compared using Student's $t$ test.
\end{abstract}

\footnotetext{
J. E. M. Brouwers · B. v. Rietbergen

Eindhoven University of Technology,

Eindhoven, The Netherlands

J. E. M. Brouwers $\cdot$ M. Ruchelsman • M. L. Bouxsein $(\square)$

Orthopedic Biomechanics Laboratory,

Beth Israel Deaconess Medical Center and Harvard Medical

School,

330 Brookline Ave,

Boston, MA 02215, USA

e-mail: mbouxsei@bidmc.harvard.edu
}

Results Morphology and fatigue properties were the same in both groups. Samples failed between $10 \mathrm{~min}$ and $15 \mathrm{~h}$. Force-displacement curves displayed typical fatigue behavior. Displacement increased over time due to mostly creep and to decreasing secant stiffness.

Conclusions We established a technique to determine compressive fatigue properties in the rat vertebral body. Our initial results indicate that ZOL-treated OVX rats have similar vertebral fatigue properties as SHAM-OVX controls.

Keywords Bone microstructure $\cdot$ Fatigue properties . Osteoporosis $\cdot$ Rats $\cdot$ Zoledronic acid

\section{Introduction}

Osteoporosis is a bone disorder that affects millions of people worldwide. It is characterized by an imbalance in bone resorption and formation rates [1, 2], resulting in low bone mass and increased fracture risk. Approximately 50\% of age-related vertebral fractures are believed to be spontaneous fractures, resulting from daily activities or from cyclic loading, rather than from trauma [3, 4].

Bisphosphonates are often used to treat osteoporotic patients. They inhibit bone resorption and thereby slow down the process of bone loss, maintaining bone mass, microstructure and strength in relevant anatomical sites like the femur and vertebra, in animals as well as in humans [5-7]. Importantly, fracture risk is significantly reduced in osteoporotic patients treated with bisphosphonates $[6,8-10]$. Zoledronic acid is a potent, relatively new bisphosphonate that recently has been shown to significantly reduce fracture risk in osteoporotic patients who received once-yearly doses [11]. We have previously shown that zoledronic acid both inhibited and recovered loss of bone structure and strength 
in ovariectomized rat tibiae and vertebrae resulting in values that were similar to control levels $[12,13]$.

Bisphosphonates have also been shown to influence the degree of mineralization of bone tissue due to decreased bone turnover rates and the subsequent prolongation of secondary mineralization $[14,15]$, which may lead to more brittle mechanical behavior [16-19]. Crystallinity of bone tissue has been shown to influence monotonic and fatigue mechanical properties in human cortical bone [20]. Microcracks and diffuse damage are commonly seen in human bone [21-23] and may act as a stimulus for bone remodeling [24]. Studies in dogs have shown that low resorption rates induced by bisphosphonates lead to accumulation of microcracks and diffuse damage [25]. It is unknown whether these increases in mineralization and microdamage resulting from bisphosphonates influence the mechanical properties of bone when cyclically loaded.

Compressive and tensile fatigue behavior has been well documented for cortical bone from humans as well as animals [26-29]. More recently, the fatigue behavior of trabecular bone in animals and humans has been found to exhibit similar characteristics as cortical bone [30-33]. Although these studies have provided fundamental information regarding bone fatigue behavior, the integral function of cortical and trabecular bone, i.e., the way they act together, which plays an important role in the vertebra, has not yet been determined. Moreover, drug efficacy studies in rats generally focus on changes in bone mass, structure, and static mechanical strength, whereas fatigue behavior, which may play an important role in vertebral fractures, may respond differently to pharmacologic intervention than other statically determined mechanical parameters.

Our primary aim was to develop an experimental approach to determine compressive fatigue mechanical properties in whole rat vertebra. We then used this method to compare fatigue properties in ovariectomized rats treated with zoledronic acid to SHAM, ovariectomized controls, which exhibited similar structural and static, compressive properties.

\section{Materials and methods}

Seventeen female, 35-week-old, Wistar rats were used from a previous study described elsewhere [12]. At week 0, eight rats were ovariectomized (OVX-ZOL), and nine rats were SHAM-ovariectomized (SHAM-OVX). Zoledronic acid was kindly provided as the disodium salt hydrate by Novartis Pharma AG (Basel, Switzerland) and was dissolved in a saline vehicle prior to injection. It was administered at a single dose of $20 \mu \mathrm{g} / \mathrm{kg}$ body weight s.c. at the time of OVX to all rats of the OVX-ZOL group. The dose was chosen based on a dose-response study in rats, in which $20 \mu \mathrm{g} / \mathrm{kg}$ body weight was found to be most effective [34]. Rats were humanely sacrificed 16 weeks later, and whole L4 vertebrae were dissected, soaked in $0.9 \%$ saline solution gauze, and frozen at $-20^{\circ} \mathrm{C}$. This study was approved by the Animals Ethics Committee of the University of Maastricht, the Netherlands.

\section{Micro-CT scanning}

Vertebrae were thawed to room temperature and scanned with a desktop micro-CT system (microCT40, Scanco Medical AG, Bruettisellen, Switzerland) at an isotropic resolution of $16 \mu \mathrm{m}(55 \mathrm{kV}, 145 \mu \mathrm{A}, 500$ projections per $180^{\circ}, 200 \mathrm{~ms}$ integration time). After scanning, samples were frozen again until mechanical testing. Images were Gaussian filtered (sigma $=0.8$, support $=1$ voxel) and binarized to separate bone from background using a global thresholding procedure [35].

From the CT scans, the trabecular region was manually selected starting ten slices below the cranial growth plate and ending ten slices above the caudal growth plate, resulting in a trabecular region of approximately $5 \mathrm{~mm}$ in axial direction. From this region, six bone structural parameters (bone volume fraction (BV/TV), connectivity density (Conn.D), structure model index (SMI), trabecular number (Tb.N), trabecular thickness (Tb.Th), and separation (Tb.Sp)) were automatically determined. Cortical bone was semi-automatically delineated from the CT scans by drawing contour lines, using the same set of slices as used for trabecular bone measurements.

\section{Specimen preparation}

To achieve plano-parallel ends, vertebrae were fixed in a custom-made jig. A double-blade, wafering, low-speed diamond saw (Isomet, Buehler, Lake Bluff, IL, USA) was used under constant saline irrigation to remove cranial and caudal ends including the growth plate. After sawing, the exact vertebral height was measured using a caliper and found to be $4.06 \pm 0.09 \mathrm{~mm}$ (mean $\pm \mathrm{SD}$ ). An example of a processed vertebra can be seen in Fig. 1. A single-blade, wafering, low-speed diamond saw was used under constant saline irrigation to remove all posterior pedicles and processes. Anterior elements were clipped off using a rounger, resulting in a separated vertebral body. CT scans taken for pilot samples had shown no splintering resulted from sawing and clipping. Vertebrae were kept frozen in a $0.9 \%$ saline solution until fatigue testing.

\section{Fatigue compression tests}

Vertebrae were thawed to room temperature prior to mechanical testing. In total, all samples were frozen and thawed for three cycles. Previously, five cycles of freezing 

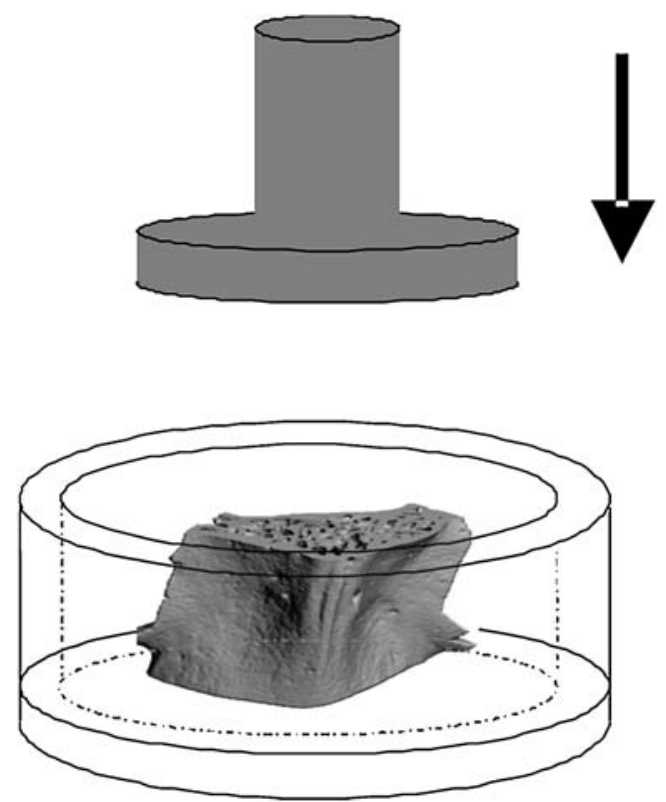

Fig. 1 Schematic of fatigue loading test. The lower platen, designed as a cup, contained the vertebra. The top platen, smaller in diameter than the cup, was lowered onto the vertebra to a compressive preload of $5 \mathrm{~N}$, at which point the displacement was set at zero. A $0.9 \%$ saline solution containing protease inhibitors was added to the cup to prevent the vertebra from dehydrating and to inhibit microorganism growth

and thawing has been found not to affect mechanical properties determined in a static, compression [36], and indentation test [37]. Therefore, we assumed that fatigue properties determined in our study were not affected by the freezing and thawing. L4-vertebral bodies were used for fatigue compression tests, which were conducted in loadcontrol at $25^{\circ} \mathrm{C}$. A custom-made, steel lower plate was designed in the form of a cup (Fig. 1). The vertebral body was placed with the cranial end facing upward in the lower cup of the testing machine (Instron 8874, Instron Corp. Canton, MA, USA). The top platen, smaller in diameter than the cup, was lowered onto the vertebra to a compressive preload of $5 \mathrm{~N}$, at which point the displacement was set at zero. Displacement was measured from the actuator displacement transducer of the testing machine. A $0.9 \%$ saline solution containing protease inhibitors was added to the cup to prevent the vertebra from dehydrating and to inhibit microorganism growth. Since bone is known to fail at a certain strain rather than at a certain load or stress $[38,39]$ and since our aim was to compare the fatigue properties at the tissue rather than structural level between the two groups, all tests were started at the same apparent strain. In a pilot study, the relation between initial apparent strain and number of cycles to failure was studied. Thirteen samples were tested between $0.6 \%$ and $0.94 \%$ initial apparent strain. A significant correlation $\left(r^{2}=0.48, p=0.009\right)$ was found between the $\log$ of strain and $\log$ of number of cycles, which corresponds to typical fatigue behavior [27, 30-33].
It was found that $0.75 \%$ initial apparent strain resulted in a reasonable number of cycles to failure (average number of cycles $\sim 40,000$ ), and therefore, this value was used in all tests. Since the stiffness varied per sample and the test was run in load-control, the load needed to reach the initial apparent strain criterion varied as well. Therefore, prior to testing, each sample was cyclically loaded for about 400 cycles with increasing load until the load was reached at which the desired apparent strain was met. The maximum load ranged from 63 to $97 \mathrm{~N}$.

During the test, load cycled between $5 \mathrm{~N}$ and the determined maximum load in a sinusoidal shape at a frequency of $2 \mathrm{~Hz}$. Tests were ended after the sample failed, which was characterized firstly by an increasing displacement range per cycle, increased hysteresis, and increased total apparent strain. Then, the sample could not bear the loads anymore and was crushed. A full loaddisplacement cycle could not be reached anymore, after which the test was stopped. Tests were stopped after 120,000 cycles if failure had not occurred. Every fourth cycle, force and displacement were acquired during one cycle at a sampling frequency of $100 \mathrm{~Hz}$.

For each sample, creep characteristics exhibited three classical phases: an initial phase of high creep rate, a phase of a lower creep rate, and a phase in which creep rate was high again, finally resulting in failure (Figs. 2 and 3) [33, 40]. From each apparent strain versus time curve, the steady-state creep rate of the secondary phase was determined by fitting a linear line through the central part of the curve. According to the method of Bowman et al. [33], a line parallel to this line was drawn at $0.5 \%$ higher offset. The intersection of this line with the apparent strain curve was defined as the time to failure and the apparent strain at failure. Young's modulus could not be properly calculated, as the effective area in a vertebra that contains trabecular and cortical bone varies going from cranial to caudal ends. Therefore, secant stiffness was calculated for each recorded cycle by dividing the load range by the displacement range of that cycle. Initial secant stiffness was determined at the start of the experiment, and final secant stiffness was determined at the time of failure. For each sample, time to failure, apparent strain at failure, steadystate creep rate, initial stiffness, and percent loss of stiffness at failure were calculated.

\section{Data analysis}

Pearson correlation coefficients were used to determine the relation between trabecular bone microarchitecture, cortical thickness, and compressive fatigue properties. For this, all structural properties were correlated with fatigue properties as well as with log-transformed values of the fatigue properties. Also, all structural and fatigue parameters were 
Fig. 2 Three representative forcedisplacement cycles throughout the testing period: 20,55 , and 10,620 cycles for a typical sample. Forcedisplacement cycles display typical fatigue behavior characterized by decreasing secant stiffness, increasing hysteresis, and increasing nonlinearity. Displacement increases over time due to mostly creep and to a lower extent, a decreasing secant stiffness

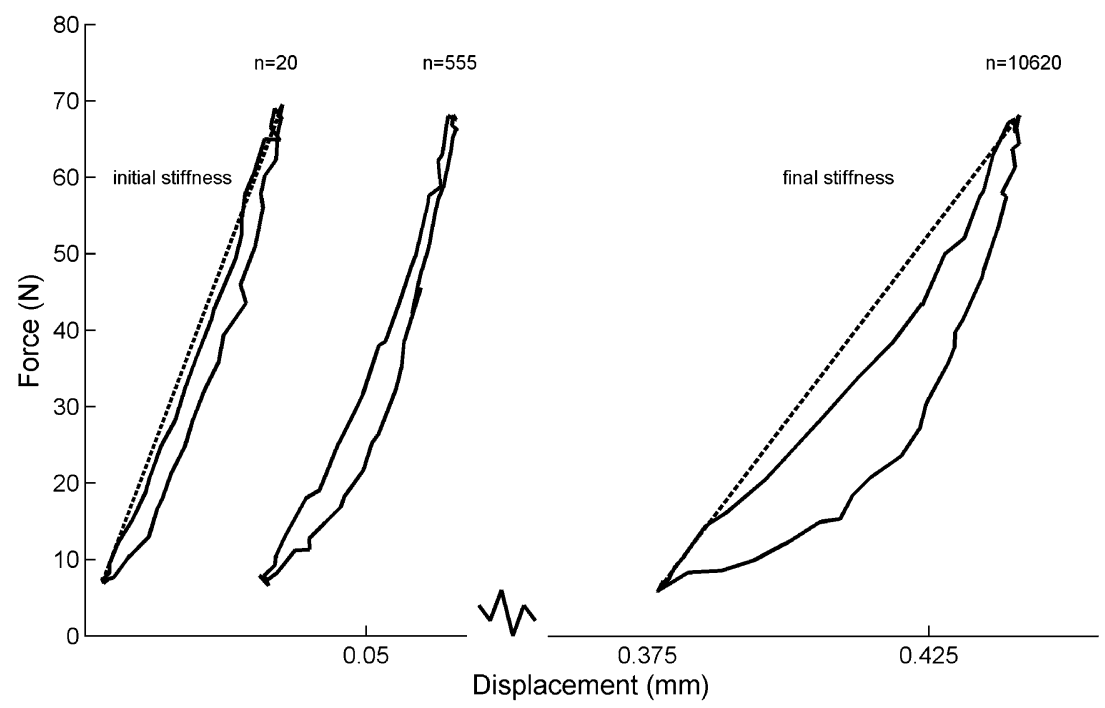

compared between the two groups using a Student's $t$ test. $p$ values below 0.05 were considered significant.

\section{Results}

During fatigue testing, 12 samples failed between $10 \mathrm{~min}$

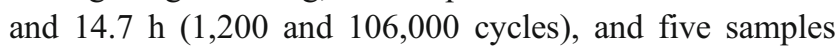
did not fail within the studied period of time. The latter samples showed a decreasing, rather than an increasing, apparent strain range per cycle during the test, accompanied by an increasing secant stiffness, suggesting that artifacts

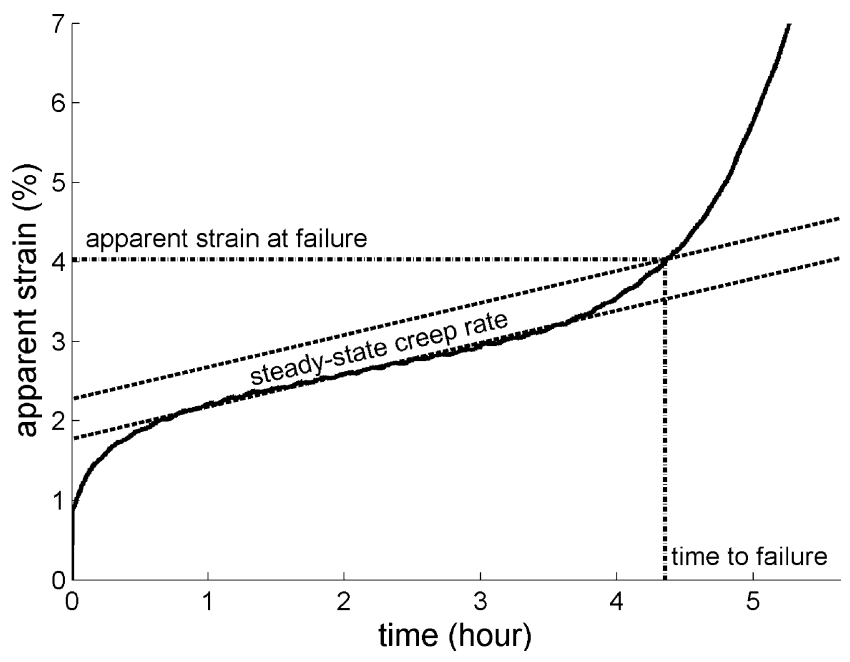

Fig. 3 Typical sample for which creep characteristics exhibit three typical phases of fatigue: an initial phase of high creep rate, a phase of a steady-state lower creep rate, and a phase in which creep rate is high again, finally resulting in failure [33, 40]. From each apparent strain against time curve, the creep rate of the secondary phase is determined by fitting a linear line. According to the method of Bowman et al. [33], a line parallel to this line is drawn at $0.5 \%$ higher offset. The intersection of this line with the apparent strain curve is defined as the time to failure and the strain at failure were present in these tests [41]. These samples were subsequently removed from all analyses in the study, resulting in seven samples in the SHAM-OVX and five in the OVX-ZOL group.

Trabecular and cortical microarchitecture

No significant differences were found in trabecular bone microarchitecture and cortical thickness between the SHAM-OVX- and the OVX-ZOL-treated group except for $\mathrm{Tb}$.Th, which was significantly higher in the ZOL-treated group (Table 1). These results indicate that ZOL treatment inhibited bone loss and trabecular deterioration that has previously been shown to occur after ovariectomy [13].

\section{Fatigue compression tests}

For all failed samples, force-displacement cycles displayed typical fatigue behavior characterized by decreasing secant stiffness, increasing hysteresis, and increasing nonlinearity (Fig. 2). Displacement increased over time due to mostly creep and to a lower extent, decreasing secant stiffness. For each sample, the steady-state creep rate was determined from the apparent strain versus time curve, as well as the time to failure and apparent strain at failure (Fig. 3).

Time to failure, apparent strain at failure, steady-state creep rate, initial stiffness, and percent loss of stiffness at failure were not significantly different between the two groups (Table 2). Steady-state creep rate and log of the time to failure have shown to be inversely linearly correlated in compressive fatigue studies on bovine trabecular bone [32, 33]. Here, we also found a strong inverse correlation between log of the steady-state creep rate and $\log$ of the time to failure of all samples taken together $\left(r^{2}=0.86, p<0.001\right.$, Fig. 4). The relationship between steady-state creep rate and time to failure was similar between SHAM-OVX and OVX-ZOL. 
Table 1 Cortical thickness, trabecular bone volume, and trabecular microarchitecture as determined by micro-CT in L4 vertebrae (mean $\pm \mathrm{SD}$ ) from SHAM-OVX and OVX-ZOL rats

\begin{tabular}{llllllll}
\hline & BV/TV $(-)$ & $\begin{array}{l}\text { Conn.D } \\
\left(1 / \mathrm{mm}^{3}\right)\end{array}$ & SMI $(-)$ & Tb.N $(1 / \mathrm{mm})$ & $\begin{array}{l}\text { Tb.Th } \\
(\mu \mathrm{m})\end{array}$ & $\begin{array}{l}\text { Tb.Sp } \\
(\mu \mathrm{m})\end{array}$ & $\begin{array}{l}\text { Cortical thickness } \\
(\mu \mathrm{m})\end{array}$ \\
\hline SHAM-OVX $(n=7)$ & $0.288( \pm 0.034)$ & $60.5( \pm 25.0)$ & $0.554( \pm 0.319)$ & $3.27( \pm 0.583)$ & $\mathbf{8 9 . 4}( \pm \mathbf{5 . 3})$ & $\begin{array}{l}290( \pm 46) \\
174( \pm 12) \\
\text { OVX-ZOL }(n=5)\end{array}$ \\
\hline
\end{tabular}

Parameters in bold are significantly different between groups ( $p<0.05$ by unpaired $t$ test)

Relation between morphology and fatigue properties

BV/TV, Conn.D, Tb.N, and Tb.Sp each correlated with apparent strain at failure as well as with log of the apparent strain at failure $\left(0.31<r^{2}<0.50, p<0.05\right)$. All other correlations between morphologic parameters and fatigue properties were not significant (Fig. 5).

\section{Discussion}

In this study, we developed a method for assessing the fatigue properties of whole rat vertebrae. Typical fatigue behavior was seen in SHAM-ovariectomized as well as in ZOL-treated, ovariectomized rats. Fatigue properties, trabecular microarchitecture, and cortical thickness were similar in both groups. Previously, we showed that static compressive behavior was also similar in L3 vertebrae of the same groups of rats [13]. Altogether, this suggests that ZOL treatment of ovariectomized rats results in the same vertebral bone mass and structure as SHAM, ovariectomized rats, as well as the same vertebral static and fatigue properties.

For all vertebrae, force-displacement curves displayed typical fatigue behavior characterized by decreasing secant stiffness, increasing hysteresis, and increasing nonlinearity. This agrees with compressive, fatigue behavior previously reported for cortical and trabecular bone specimens [27, 31-33]. Also, the strong linear correlation between the log steady-state creep rate and the log time to failure agrees with the literature [32,33], which indicates the validity of the test. This also indicates that the integral fatigue behavior of cortical and trabecular bone in rats is similar to the two bone compartments assessed separately. We found an average apparent strain at failure of about $4 \%$ for both groups, which is just slightly higher than the $3.4 \%$ and $2.8 \%$ reported for, respectively, human and bovine trabecular bone $[31,33]$.

Samples that did not fail during the test were removed from further analysis and showed a decreasing rather than an increasing apparent strain range per cycle during the test accompanied by an increasing secant stiffness. This behavior suggests that artifacts were present in these tests [41, 42], possibly due to vertebral ends that were not perfectly parallel. In this case, when the force range, leading to $0.75 \%$ apparent strain, was determined at the start of the test, the actual area bearing the load would be smaller than the total bone area. During the test, the area bearing the load would then be compressed, resulting in the same load being born by the area of the whole vertebra and thus in lower strains. Improving the sawing procedure and specimen fixation in the loading device could possibly reduce the rate of exclusion of samples.

The fatigue behavior in these whole vertebrae was comparable to the fatigue behavior found in studies on cortical and trabecular bone, though no fatigue data on rat bone are available. Although not determined in our study, it would be interesting to study whether failure starts in the cortical or trabecular bone.

Most of the fatigue properties were unrelated to cortical or trabecular bone morphology, with the exception of weak relationships between trabecular bone morphology and apparent strain at failure. Vertebral morphology and microarchitecture were similar in both groups, and any intrinsic variance in bone mass and stiffness was accounted for in the fatigue test by starting all tests at the same apparent strain level. One might therefore expect that trabecular microarchitecture would not be well correlated with fatigue properties in this test protocol. However, it is possible that despite our normalized test, some types of structure are more favorable over time in a fatigue test than others,

Table 2 Compressive fatigue properties determined in L4 vertebrae (mean \pm SD) from SHAM-OVX and OVX-ZOL rats

\begin{tabular}{|c|c|c|c|c|c|}
\hline & $\begin{array}{l}\text { Time to failure } \\
\text { (h) }\end{array}$ & $\begin{array}{l}\text { Apparent strain at } \\
\text { failure }(\%)\end{array}$ & $\begin{array}{l}\text { Steady-state } \\
\text { creep rate }(\% / h)\end{array}$ & $\begin{array}{l}\text { Initial stiffness } \\
(\mathrm{N} / \mathrm{mm})\end{array}$ & $\begin{array}{l}\text { Loss of stiffness } \\
(\%)\end{array}$ \\
\hline SHAM-OVX $(n=7)$ & $5.42( \pm 4.67)$ & $4.19( \pm 1.52)$ & $0.80( \pm 1.25)$ & $2,193( \pm 285)$ & $20.11( \pm 6.68)$ \\
\hline OVX-ZOL $(n=5)$ & $5.51( \pm 5.80)$ & $4.30( \pm 1.50)$ & $0.50( \pm 0.37)$ & $2,396( \pm 191)$ & $16.96( \pm 9.59)$ \\
\hline
\end{tabular}




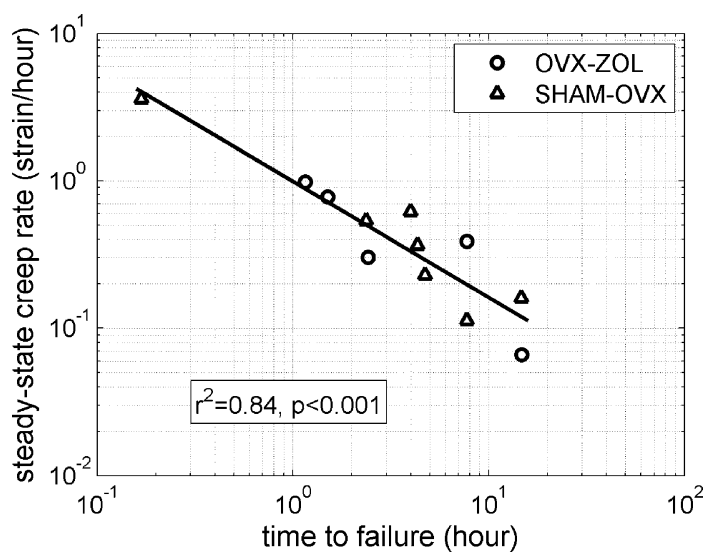

Fig. 4 Steady-state creep rate plotted against time to failure for all samples on a $\log -\log$ scale. A significant inverse linear correlation was found between $\log$ of the time to failure and $\log$ of the steadystate creep rate $\left(r^{2}=0.84, p<0.001\right)$

which could result in a correlation between a structural parameter and a fatigue property. Additional studies need to be conducted to further delineate the possible relationship between bone microarchitecture and fatigue behavior. Notably, in human trabecular bone, bone volume fraction is weakly correlated with strain at failure, which agrees with our findings [30].

Rather than applying the same load, which will result in low bone mass samples failing earlier than high bone mass samples, we applied the same apparent strain in each test. By developing this normalized fatigue test, we aimed at determining changes in fatigue properties due to differences at the tissue rather than the structural level. The fact that no difference in fatigue behavior was found between both groups indicates that either no changes occurred in the bone tissue fatigue properties or that we were unable to detect them. Increased mineralization that may have taken place in the ZOL group due to lower turnover rate apparently did not lead to detectable changes in fatigue properties of the bone tissue. It may be, however, that a longer treatment period would have led to noticeable changes. Also, no untreated OVX group was included in this study, and therefore, the effects of OVX versus those associated with ZOL treatment cannot be distinguished. Theoretically, it could be that OVX would lead to altered fatigue properties, which could have then been reversed by ZOL resulting in no differences between SHAM-OVX- and ZOL-treated OVX rats. This will need to be tested by additional studies.

In our study, several samples did not fail during the test, which reduced the sample size. Also, between-subject variation was found to be high, which, combined with the small sample size, reduced the power to detect differences between the groups. A power analysis revealed that a scientifically relevant difference of $30 \%$ between the two groups in apparent strain at failure would have been detectable if the sample size would have been 22 . Therefore, large sample sizes would have been needed to detect any scientifically relevant differences, which were not noted in this study. Also, after starting the test, all samples needed to "settle in". Thus, strains sometimes decreased or increased slightly directly after starting the test, and this may have affected the time to failure. However, this phenomenon occurred in both groups and, therefore, would not be expected to contribute to grouprelated differences. The sufficient quality of the fatigue test, however, was reflected in the fact that typical fatigue behavior was seen in terms of force-displacement curves and a strong correlation between steady-state creep rate and $\log$ of the time to failure. No observation of substantial differences between groups was found, and this study presents therefore the first indication that ZOL-treated, ovariectomized rats have similar fatigue properties as control rats. More studies are needed to further elucidate the effects of bisphosphonates on fatigue properties. The gained insight in testing limitations will allow for future study designs to be optimized.

In this study, we developed a method to determine compressive fatigue mechanical behavior of whole vertebrae in rats. Fatigue properties of whole rat vertebra exhibited similar characteristics as isolated cortical and trabecular bone specimens. Vertebral morphology, as well as fatigue proper-
Fig. 5 A nonsignificant and a significant correlation between, respectively, cortical thickness and apparent strain at failure and $\mathrm{BV} / \mathrm{TV}$ and apparent strain at failure
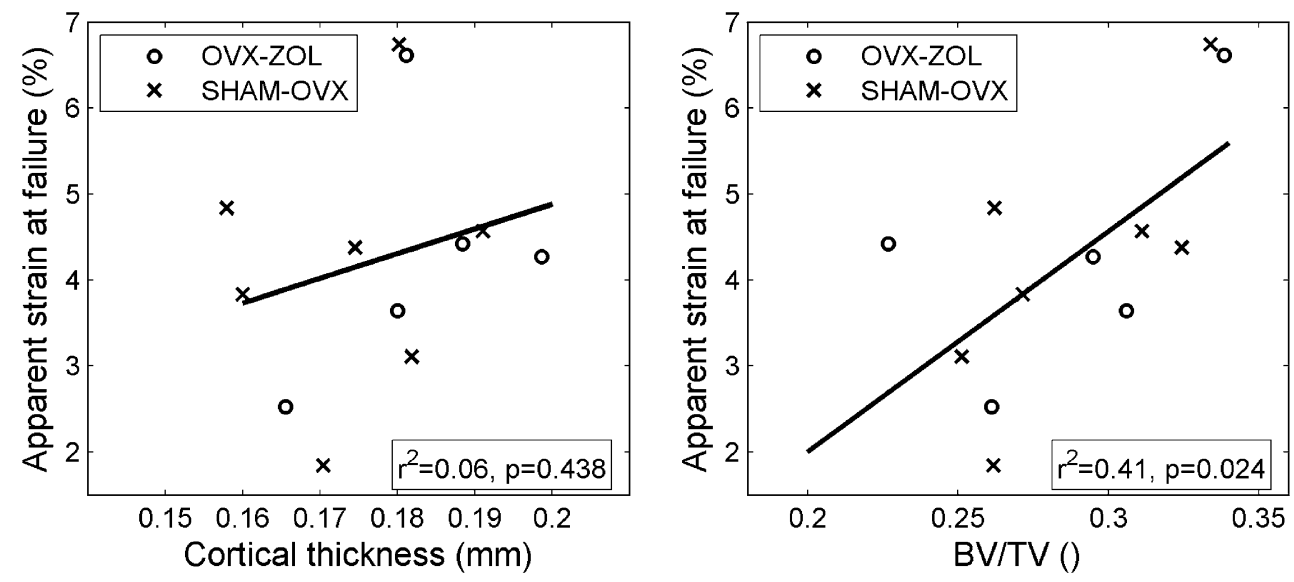
ties of ZOL-treated ovariectomized rats, were similar to SHAM-OVX rats. These findings indicate that ZOL treatment does not have a pronounced negative influence on cyclic mechanical properties, as might be expected if ZOLtreated bone tissue were more brittle or contained excessive microdamage. The development of this methodology will allow further investigation of the effects of osteoporosis treatments on vertebral compressive fatigue behavior.

Acknowledgments This work was funded by the Netherlands Organisation for Scientific Research, Prins Bernard Cultuurfonds, and VSBFonds. We thank Elise Morgan of the Boston University for her advice and for using her fatigue testing equipment. We thank Zackary Mason and John Muller for technical assistance regarding the fatigue testing.

Conflicts of interest $\mathrm{Dr}$ van Rietbergen serves as a consultant for Scanco Medical AG. All other authors state that they have no conflicts of interest.

Open Access This article is distributed under the terms of the Creative Commons Attribution Noncommercial License which permits any noncommercial use, distribution, and reproduction in any medium, provided the original author(s) and source are credited.

\section{References}

1. Wu K, Jett S, Frost HM (1967) Bone resorption rates in rib in physiological, senile, and postmenopausal osteoporoses. J Lab Clin Med 69:810-818

2. Wu K, Frost HM (1969) Bone formation in osteoporosis. Appositional rate measured by tetracycline labeling. Arch Pathol 88:508-510

3. Freeman MA, Todd RC, Pirie CJ (1974) The role of fatigue in the pathogenesis of senile femoral neck fractures. J Bone Joint Surg Br 56-B:698-702

4. Riggs BL, Melton LJ (1995) The worldwide problem of osteoporosis: insights afforded by epidemiology. Bone 17:S505-S511

5. Hordon LD, Itoda M, Shore PA, Shore RC, Heald M, Brown M, Kanis JA, Rodan GA, Aaron JE (2006) Preservation of thoracic spine microarchitecture by alendronate: comparison of histology and microCT. Bone 38:444-449

6. Russell RGG (2006) Ibandronate: pharmacology and preclinical studies. Bone 38:S7-S12

7. Borah B, Dufresne TE, Chmielewski PA, Johnson TD, Chines A, Manhart MD (2004) Risedronate preserves bone architecture in postmenopausal women with osteoporosis as measured by threedimensional microcomputed tomography. Bone 34:736-746

8. Boonen S (2007) Bisphosphonate efficacy and clinical trials for postmenopausal osteoporosis: similarities and differences. Bone 40:S26-S31

9. Perez-Lopez FR (2004) Postmenopausal osteoporosis and alendronate. Maturitas 48:179-192

10. Giavaresi G, Fini M, Gnudi S, Nicoli Aldini N, Rocca M, Carpi A, Giardino R (2001) Comparison of calcitonin, alendronate and fluorophosphate effects on ovariectomized rat bone. Biomed Pharmacother 55:397-403

11. Black DM, Delmas PD, Eastell R, Reid IR, Boonen S, Cauley JA, Cosman F, Lakatos P, Leung PC, Man Z, Mautalen C, Mesenbrink $\mathrm{P}, \mathrm{Hu} \mathrm{H}$, Caminis J, Tong K, Rosario-Jansen T, Krasnow J, Hue
TF, Sellmeyer D, Eriksen EF, Cummings SR, HORIZON Pivotal Fracture Trial (2007) Once-yearly zoledronic acid for treatment of postmenopausal osteoporosis. N Engl J Med 356:1809-1822

12. Brouwers JEM, Lambers JM, Gasser JA, van Rietbergen B, Huiskes R (2008) Bone degeneration and recovery after early and late bisphosphonate treatment of ovariectomized wistar rats assessed by in vivo micro-computed tomography. Calcif Tissue Int 82:202-211

13. Brouwers JEM, Rietbergen Bv, Bouxsein ML (2008) Influence of early and late zoledronic acid administration on vertebral structure and strength in ovariectomized rats. Calcif Tissue Int 83:186-191

14. Boivin G, Arlot M, Trechsel U, Meunier PJ (2003) Effects of intravenous zoledronic acid on the degree of mineralization of bone in post-menopausal osteoporosis: a quantitative microradiographic analysis of transiliac biopsies after one year. J Bone Miner Res 2(Suppl):S261

15. Bauss F, Dempster DW (2007) Effects of ibandronate on bone quality: preclinical studies. Bone 40:265-273

16. Burr DB, Miller L, Grynpas M, Li J, Boyde A, Mashiba T, Hirano $\mathrm{T}$, Johnston CC (2003) Tissue mineralization is increased following 1-year treatment with high doses of bisphosphonates in dogs. Bone 33:960-969

17. Benhamou CL (2007) Effects of osteoporosis medications on bone quality. Joint Bone Spine 74:39-47

18. Little DG, Smith NC, Williams PR, Briody JN, Bilston LE, Smith EJ, Gardiner EM, Cowell CT (2003) Zoledronic acid prevents osteopenia and increases bone strength in a rabbit model of distraction osteogenesis. J Bone Miner Res 18:1300-1307

19. Allen MR, Iwata K, Phipps R, Burr DB (2006) Alterations in canine vertebral bone turnover, microdamage accumulation, and biomechanical properties following 1-year treatment with clinical treatment doses of risedronate or alendronate. Bone 39:872-879

20. Yerramshetty JS, Akkus O (2008) The associations between mineral crystallinity and the mechanical properties of human cortical bone. Bone 42:476-482

21. Cheng XG, Nicholson PH, Lowet G, Boonen S, Sun Y, Ruegsegger P, Muller R, Dequeker J (1997) Prevalence of trabecular microcallus formation in the vertebral body and the femoral neck. Calcif Tissue Int 60:479-484

22. Fazzalari NL, Forwood MR, Smith K, Manthey BA, Herreen P (1998) Assessment of cancellous bone quality in severe osteoarthrosis: bone mineral density, mechanics, and microdamage. Bone 22:381-388

23. Mori S, Harruff R, Ambrosius W, Burr DB (1997) Trabecular bone volume and microdamage accumulation in the femoral heads of women with and without femoral neck fractures. Bone 21:521-526

24. Mori S, Burr DB (1993) Increased intracortical remodeling following fatigue damage. Bone 14:103-109

25. Mashiba T, Hirano T, Turner CH, Forwood MR, Johnston CC, Burr DB (2000) Suppressed bone turnover by bisphosphonates increases microdamage accumulation and reduces some biomechanical properties in dog rib. J Bone Miner Res 15:613-620

26. Pattin CA, Caler WE, Carter DR (1996) Cyclic mechanical property degradation during fatigue loading of cortical bone. J Biomech 29:69-79

27. Caler WE, Carter DR (1989) Bone creep-fatigue damage accumulation. J Biomech 22:625-635

28. Carter DR, Caler WE, Spengler DM, Frankel VH (1981) Uniaxial fatigue of human cortical bone. The influence of tissue physical characteristics. J Biomech 14:461-470

29. Schaffler MB, Radin EL, Burr DB (1990) Long-term fatigue behavior of compact bone at low strain magnitude and rate. Bone 11:321-326

30. Rapillard L, Charlebois M, Zysset PK (2006) Compressive fatigue behavior of human vertebral trabecular bone. J Biomech 39:2133-2139 
31. Haddock SM, Yeh OC, Mummaneni PV, Rosenberg WS, Keaveny TM (2004) Similarity in the fatigue behavior of trabecular bone across site and species. J Biomech 37:181-187

32. Bowman SM, Keaveny TM, Gibson LJ, Hayes WC, McMahon TA (1994) Compressive creep behavior of bovine trabecular bone. J Biomech 27:301-305

33. Bowman SM, Guo XE, Cheng DW, Keaveny TM, Gibson LJ, Hayes WC, McMahon TA (1998) Creep contributes to the fatigue behavior of bovine trabecular bone. J Biomech Eng 120:647-654

34. Gasser JA, Ingold P, Venturiere A, Shen V, Green JR (2008) Longterm protective effects of zoledronic acid on cancellous and cortical bone in the ovariectomized rat. J Bone Miner Res 23:544-551

35. Muller R, Ruegsegger P (1997) Micro-tomographic imaging for the nondestructive evaluation of trabecular bone architecture. Stud Health Technol Inform 40:61-79

36. Linde F, Sorensen HC (1993) The effect of different storage methods on the mechanical properties of trabecular bone. J Biomech 26:1249-1252
37. Kang Q, An YH, Friedman RJ (1997) Effects of multiple freezing-thawing cycles on ultimate indentation load and stiffness of bovine cancellous bone. Am J Vet Res 58:1171-1173

38. Keaveny TM, Guo XE, Wachtel EF, McMahon TA, Hayes WC (1994) Trabecular bone exhibits fully linear elastic behavior and yields at low strains. J Biomech 27:1127-1129

39. Keaveny TM, Wachtel EF, Ford CM, Hayes WC (1994) Differences between the tensile and compressive strengths of bovine tibial trabecular bone depend on modulus. J Biomech 27:1137-1146

40. Keaveny TM (2001) Strength of trabecular bone. In: Cowin SC (ed) Bone mechanics handbook. CRC, Boca Raton, FL ch 16

41. Guo XE, Gibson LJ, McMahon TA (1993) Fatigue of trabecular bone: avoiding end-crushing artifacts. Trans 39th Orthop Res Soc $18: 584$

42. Keaveny TM, Pinilla TP, Crawford RP, Kopperdahl DL, Lou A (1997) Systematic and random errors in compression testing of trabecular bone. J Orthop Res 15:101-110 